\title{
BOS to hold first hybrid annual conference
}

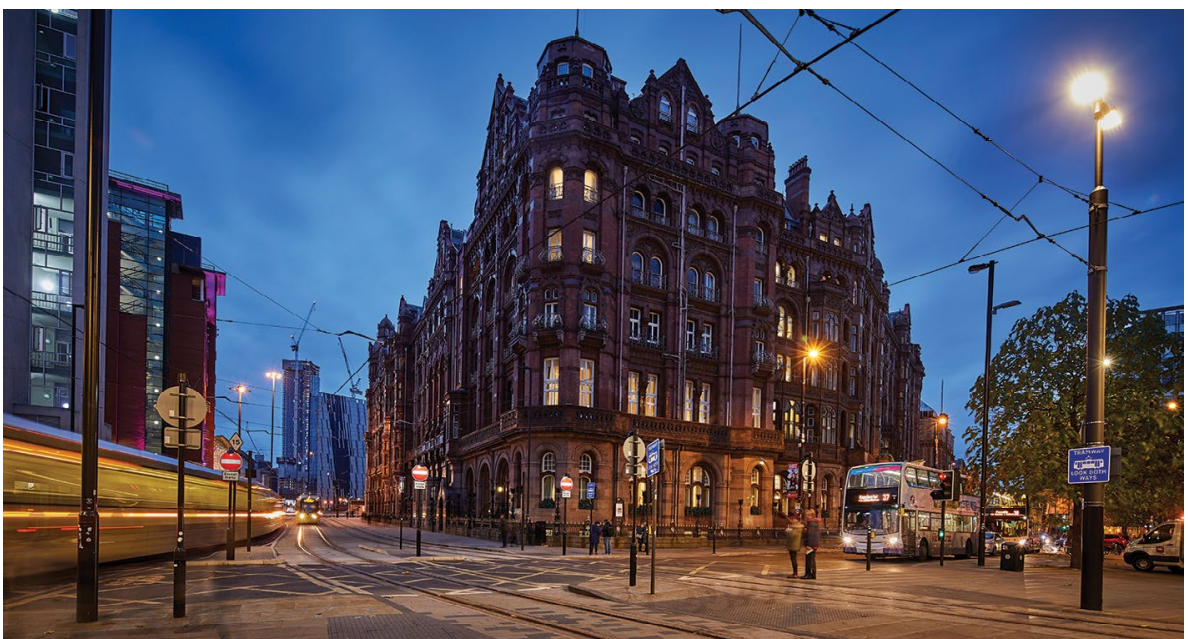

The British Orthodontic Society (BOS) have just announced that this year's British Orthodontic Conference, to be held in the iconic Midland Hotel in Manchester on 16-18 September 2021, will be the event's first ever hybrid offering.

Following such an unusual year, the BOS would like to invite everyone with an interest in orthodontics - consultants, specialists, training grades, GDPs, therapists and nurses - to come along, listen to a fantastic programme live, visit Manchester, socialise and meet friends and colleagues again.
The hybrid element event will allow those delegates who, for whatever reason, can't travel, or overseas delegates, to be able to register and access the BOC lecture programme virtually, as well as attend a virtual trade exhibition and network with colleagues online.

The conference programme includes Phil Hammond (Private Eye's MD, physician, broadcaster, comedian and commentator on health issues), and the prestigious Northcroft Lecture will be presented by BOS President, Professor Jonathan Sandler. There will also be parallel sessions: 'Driving private practice', 'So you want to know about orthodontics' for aspiring orthodontists, and a two-day DCP programme.

David Waring, Chair of the British Orthodontic Conference Committee, said: 'We were so disappointed not to have a conference in 2020 and we have worked extremely hard to deliver a conference in 2021 that is doubly good! Everyone can book with confidence - if we have to make any changes or hold a purely virtual event, you will always be able to transfer to the online event and get the appropriate refund. We recognise the importance of flexibility when it comes to plans and hope this provides the reassurance colleagues need.

'We feel that we have something for all the team at this year's conference and look forward to welcoming everyone.'

Registration opened at the start of May for the 2021 British Orthodontic Conference - visit www.bos.org.uk/News-and-Events/ Events-Meetings to find out more and to book.

An early bird discount will be available for all bookings made before 23 July and a combined team rate is on offer too so that the whole team can attend, learn, and have fun.

\section{New centre of excell
squamous cancer}

Barts Centre for Squamous Cancer is a new centre of excellence dedicated to improving detection, treatment, and quality of life for patients with squamous cancer.

Squamous cancers are the most frequent human solid tumours and a major cause of mortality. Squamous cancers can form in the mucosa of the oral cavity and oesophagus, skin, the lungs, and the cervix. Recent pioneering Barts research has shown that these tumours have common determinants, and this has raised exciting opportunities for new strategies for cancer prevention, detection and treatment.

Barts Centre for Squamous Cancer is a cross-institute collaborative centre at Queen Mary University of London, bringing together research groups with diverse expertise from across the School

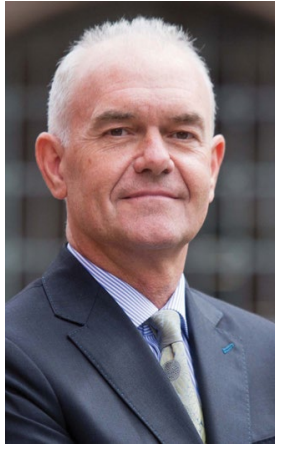

Paul Coulthard

of Medicine and Dentistry to tackle the problem of squamous cancer and drive clinical innovation.

The new centre has its home in the Institute of Dentistry and is set up with over $£ 2.6$ million funding from the Barts Charity recently awarded to Paul Coulthard, Dean and Director of the Institute of Dentistry and Professor of Oral \& Maxillofacial

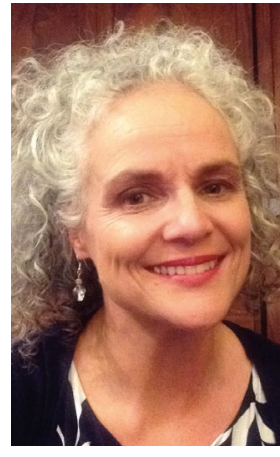

Catherine Harwood
David Kelsell

Surgery; Irene Leigh, Professor of Cellular Molecular Medicine who will be Director of the Centre; David Kelsell, Professor of Human Molecular Genetics; and Catherine Harwood, Professor of Dermatology.

A virtual Launch Symposium took place on 28 April 2021 with a Keynote Presentation from Jennifer Grandis (UCSF). 